D.O.I.: $10.3895 / \mathrm{S} 1808-04482011000400002$

\title{
UTILIZAÇÃO DO MESMO PRESTADOR DE SERVIÇOS LOGÍSTICOS (PSL) POR EMPRESAS CONCORRENTES
}

\section{USING THE SAME LOGISTICS SERVICE PROVIDER (LSP) BY COMPETITORS}

\author{
Mauro Vivaldini ${ }^{1}$; Silvio Roberto Ignácio Pires ${ }^{2}$ \\ ${ }^{1}$ Universidade Metodista de Piracicaba - UNIMEP - Piracicaba - Brasil \\ mavivald@unimep.br \\ ${ }^{2}$ Universidade Metodista de Piracicaba - Piracicaba - Brasil \\ sripires@unimep.br
}

\begin{abstract}
Resumo:
Considerando que a gestão logística atribuída a um PSL (Prestadores de Serviços Logísticos) aparece como alternativa a ser adotada pelas empresas, este artigo analisa a contratação do mesmo PSL por empresas concorrentes. Através de um estudo de multi-casos pesquisou-se oito empresas no mercado de alimentação e um PSL que atende este mercado, na intenção de obter os fatores que mais contribuem na decisão para se escolher ou não o mesmo provedor. O estudo apresenta os principais fatores pesquisados e conclui que a decisão de escolha ou não do PSL que atende a concorrentes não é percebido como um problema que afetará os negócios da empresa contratante. As empresas pesquisadas destacam mais fatores que favorecem a escolha de atuar com o mesmo PSL do que aqueles que impeçam a decisão. Todos os fatores apresentados são percebidos pelas empresas como motivadores para a escolha do mesmo PSL e os benefícios percebidos na incorporação desses diferenciais tem maior impacto na decisão do que o fato dele atender a um concorrente.
\end{abstract}

Palavras chaves: prestador de serviço logístico; concorrentes; logística.

\section{Introdução}

Ultimamente, a consolidação e prática dos conceitos relacionados à Gestão da Cadeia de Suprimentos têm levado a indústria de Prestadores de Serviços Logísticos (PSL) a assumir um papel mais abrangente e integrado com seus clientes. Nesta linha, vem surgindo novas configurações do papel destes PSL, como o de Integradores Logísticos, com um papel combinando gestão e operação das necessidades logísticas da cadeia de suprimentos. Estes provedores não representam mais uma simples terceirização de serviços logísticos, mas sim uma relação de negócio comprometida e integrada com o negócio de seu cliente (VIVALDINI; PIRES, 2010).

As atividades logísticas constituem o principal produto do PSL e, por serem inúmeras, elas tornam-se possibilidades de negócio e uma porta capaz de abrir relacionamentos com potenciais clientes. Portanto, é fundamental a esses provedores entenderem que papel e atividades podem 
executar no fluxo da Cadeia de Suprimentos (CS) do cliente, e nele atuar buscando incorporar cada vez mais atividades. À medida que desenvolvem mais atividades num mesmo cliente o PSL adquire conhecimento e especialização no segmento, conseqüentemente esta diferenciação tende a atrair outros clientes, alguns deles do mesmo segmento.

Através de um estudo com oito grandes empresas na área de alimentação fora de casa (restaurantes tipo casual dinner e fast-food) e um PSL, o artigo explora o tema referente à utilização do mesmo PSL por empresas concorrentes, na intenção de apresentar os fatores que mais contribuem para esta decisão. Assim, com a pesquisa de campo e o estudo da teoria a respeito dos PSL, pretende-se estabelecer um comparativo da prática com o que se descreve na literatura a respeito dos atributos que definem a contratação de um PSL.

Vale destacar que não é um estudo que pretende definir posição a respeito dos PSL ou de questões relacionadas à concorrência de mercado, mas sim contribuir para o melhor entendimento dos fatores que favorecem a escolha de um PSL. Além disso, o momento para explorar o tema é relativamente oportuno pelo estágio de desenvolvimento que vem alcançando estes provedores e principalmente pelas diferentes atividades que estão sendo atribuídas a eles. Também, por outro lado, o estudo tem a intenção de saber, por acreditar que exista relativa dúvida por parte dos PSL e dos clientes, se o fato de atuar com empresas concorrentes na prestação de serviço influencia ou cria embaraço no relacionamento.

\section{Metodologia}

Os autores deste trabalho vêem pesquisando os processos logísticos em redes de foodservice (alimentação em redes de refeição como restaurantes e fast-food) há cerca de cinco anos. Nesse período de pesquisas, os autores acompanharam e analisaram a cadeia de suprimentos de grandes empresas do setor, bem como a forma que conduzem e decidem suas operações. Assim, a pesquisa foi organizada na forma de um estudo de multi-casos, por pesquisar oito redes comerciais de alimentação fora de casa e um PSL.

Baseando-se na sua atual importância no campo da pesquisa em gestão, Lapierre (2005) defende o estudo de caso como uma abordagem empírica direta que forma a base para a produção de documentos e avanço do conhecimento. O método de casos é baseado na abertura e receptividade do contato direto de pessoas e experiências concretas. Dá-se preponderância à própria prática e ao estudo rigoroso do fenômeno (em que se examina caso a caso), a inteligência das ações daqueles que foram bem sucedidos ou fracassaram, analisando o que se passa na vida real, para extrair orientações, posições pessoais e novas sínteses que então podem ser colocadas a serviço de suas próprias práticas.

A Figura 1 ilustra a organização da pesquisa adotada para este trabalho, segundo sugere 
Eisenhardt (1983) para estudo de casos.

Figura 1 - Estrutura básica da pesquisa

\begin{tabular}{|c|c|c|}
\hline \multicolumn{2}{|c|}{ Utilização do mesmo PSL por empresas concorrentes } \\
\hline \hline $\begin{array}{c}\text { Estudo teórico sobre } \\
\text { PSL }\end{array}$ & $\begin{array}{c}\text { Fstudo de campo que } \\
\text { influênciam a decisão } \\
\text { (teoria x prática) }\end{array}$ \\
\hline 8 empresas \\
\hline 1 PSL \\
\hline
\end{tabular}

Fonte: Autoria própria (2010)

Desenvolve-se um estudo a respeito dos PSL na intenção de entender como a literatura descreve e como o mercado entende este provedor de serviços. Em seguida, com o embasamento da teoria, pesquisa-se oito empresas ligadas ao segmento de alimentação fora de casa, e um PSL, para que através dessa pesquisa de campo obtenha-se informações que reflitam fatores que conduzem as empresas a decidiram ou não por provedores que atuam com concorrentes. Analisada as informações o estudo compara a visão teórica com o obtido na prática.

O longo período de pesquisa e interação com as empresas permitiu aos autores entenderem não só o negócio de cada uma, bem como ajudou a avaliarem o comportamento dessas empresas diante de seus mercados de atuação. Durante a pesquisa, a interação com diversos funcionários esclareceu dúvidas e alinhou a pesquisa teórica com o que se observou na prática. Para se chegar a isso, a pesquisa foi organizada como segue Eisenhardt (1983):

a) - Análise da literatura: foi feito um estudo sobre a teoria a respeito de Prestadores de serviços logísticos, com a intenção de delimitar o tema e classificar os fatores para a escolha de um PSL.

b) - Planejamento da pesquisa: o interesse dos autores pelas empresas deve-se ao fato delas serem referências na área de food-service (alimentação fora de casa) e na prestação de serviços logístico neste mesmo segmento. O relacionamento dos autores com as empresas, por muitos anos, facilitou contatos, coleta de dados e informações.

- Coleta de dados, informações e registro: foi realizada mediante entrevistas (guiadas por questionários semi-estruturados) e observações diretas, transcritas pelos autores no decorrer da pesquisa.

- Filtro de informações: após obter diversas informações e dados, com foco no objetivo da pesquisa (escolha de PSL por empresas concorrentes), os autores extraíram as informações relevantes e buscaram outras entrevistas com executivos e funcionários das empresas na intenção de obter novos esclarecimentos.

c) - Análise do conteúdo e conclusões: buscou-se realizar a análise e o cruzamento dos 
dados e das informações para esclarecer divergências e dúvidas, retornando as empresas pesquisadas, quando necessário, para discussão dos resultados e entendimento das discordâncias junto aos entrevistados. Nesta etapa, a intenção foi evitar conclusões influenciadas pela teoria ou por deduções pré-estabelecidas pelos autores.

Os autores focaram as principais empresas, clientes e não clientes do PSL estudado, que atuam como redes comerciais de restaurantes do tipo casual dinner e fast food no Brasil. Foram estudadas oito redes através de entrevistas realizadas com 30 executivos, conforme Quadro 1.

\begin{tabular}{|c|c|c|c|c|c|c|c|c|}
\hline \multirow{3}{*}{$\begin{array}{l}\text { Empresas } \\
\text { pesquisadas }\end{array}$} & \multicolumn{5}{|c|}{ Clientes } & \multicolumn{3}{|c|}{ Não clientes } \\
\hline & $\mathbf{A}$ & B & C & $\mathbf{D}$ & $\mathbf{E}$ & $\mathbf{F}$ & $\mathbf{G}$ & $\mathbf{H}$ \\
\hline & \multicolumn{8}{|c|}{ Executivos entrevistados } \\
\hline Corporativos & 2 & 1 & 1 & 1 & 1 & 1 & 1 & 1 \\
\hline Ponto-de-venda & 5 & 2 & 2 & 2 & 3 & 3 & 3 & 1 \\
\hline
\end{tabular}

Fonte: autoria própria (2010)

\section{Pesquisa da Literatura}

A seguir o artigo explora a teoria a respeito do papel do PSL em cadeias de suprimentos. No primeiro tópico sobre a configuração tradicional difundida no mercado e na literatura, e num segundo sobre a importância da gestão colaborativa para este provedor.

\subsection{Sobre 3PL}

Caracterizada pelas diversas transformações organizacionais, a terceirização se consolidou em diversos setores e não foi diferente na prestação de serviços logísticos. Inicialmente, a gestão estava mais focada em armazenagem e transporte, sem muita relação com os processos estratégicos da cadeia de suprimentos. Segundo Lonsdale e Cox (2000), a terceirização tem ocorrido mais sobre as atividades de suporte do que sobre atividades primárias da cadeia. No caso dos PSL, eles podem assumir atividades primárias ou não, mas estão diretamente envolvidos no negócio do cliente. Geralmente as empresas sentem-se mais confortáveis ao terceirizar atividades menos importantes do que outras mais críticas. Apesar dessa constatação, pode-se afirmar que a terceirização com um PSL seria então, uma exceção, considerando serem muitas as atividades logísticas cruciais para os negócios da empresa.

Numa visão complementar, Svensson (2003) acredita que as empresas estão reduzindo o número de subcontratados e concentrando cada vez mais atividades em um mesmo subcontratado. No caso, isto aumenta sua dependência na cadeia e as chances de ter o PSL com um grupo maior de atividades sendo executadas para uma empresa ou uma cadeia de suprimento. Isto, também, reflete o pensamento de McIvor (2003), em que a terceirização deve levar em consideração a capacidade do contratado em integrar as atividades e sub-atividades contratadas. 
A seguir, numa adaptação dos tópicos sugeridos por diversos autores (JAAFAR; RAFIQ, 2005; VIJAYVARGIYA; DEY, 2010), tem-se um resumo das motivações e razões que levam uma empresa a terceirizar os serviços logísticos, bem como os possíveis benefícios que podem obter:

- Focar esforços em seu próprio negócio e na busca de novos mercados;

- Reduzir os custos logísticos, evitando investimentos em ativos não relacionados ao negócio da empresa;

- Ter uma CS complexa devido a uma base de supridores fragmentada, adicionando valor as operações existentes;

- Flexibiliza e consolida o processo de expedição;

- Aumento do retorno de produtos;

- Coordenar as atividades logísticas numa visão mais global;

- Melhorar e controlar os níveis dos serviços e das atividades logísticas;

- Ter maior flexibilidade e eficiência nas operações logísticas;

- Ter acesso a novas tecnologias de informação e comunicação (TIC) e conhecimento logístico.

- Ter somente um ponto de contato, fortalecendo a relação com o agente logístico.

Para Dornier et al. (2000), os serviços fornecidos por empresas de logística terceirizada (3PL) recaem em um modelo que combina serviços físicos (isto é, armazém e transporte) e gerenciais. À medida que a complexidade e a necessidade de customização das diferentes empresas aumentam a natureza integrada da logística, o número de empresas específicas que a oferecem também aumenta. Ainda para esses autores, os serviços logísticos se dividem em quatro diferentes tipos: (1) serviços básicos, que não requerem grande coordenação; (2) serviços logísticos contratuais físicos, que permitem a terceirização de alguns dos serviços físicos, enquanto a empresa ainda mantém controle da gestão; (3) serviços logísticos contratuais de gestão, que subcontratam a gestão de um armazém ou frota de transporte existente; e por último (4), logística contratual integrada, que incorpora serviços físicos e funções gerenciais sob o operador logístico.

Da terceirização mais simples até a mais sofisticada, a aquisição de serviços logísticos sempre será uma atividade extremamente complexa, por se tratar da compra de um processo, muito diferente, portanto, da compra de componentes e bens. O que um PSL fornece, na verdade, é uma série de transações, que exige do contratante, interfaces e monitoramentos mais sofisticados. Uma terceirização de sucesso será aquela, a qual as partes possuam uma clara compreensão dos objetivos, da finalidade, das expectativas e das capacitações necessárias. O processo de seleção de prestadores de serviços pode variar em relação a sua complexidade, conforme o perfil dos serviços a serem contratados e o tipo de relacionamento que se pretende desenvolver. Para fornecedores nãoestratégicos ou simples "executores de tarefas", normalmente se considera a análise de cotação de 
tarifas como única ferramenta de decisão. Busca-se o custo mais baixo, sem preocupações de longo prazo, visando a simplicidade dos serviços a serem contratados e da facilidade com que este tipo de fornecedor é substituído. Já a seleção de fornecedores estratégicos, em que pode haver a necessidade de investimentos significativos, o processo de seleção tende a ser bem mais complexo (FIGUEIREDO, 2005).

Já Ayers (2001) relata que o PSL é um grande instrumento de parceria na cadeia de suprimento pelo conhecimento e infra-estrutura que possui. Para Ballou (2001), em vez de possuir por completo a capacidade logística total e ter uma grande estrutura organizacional logística, algumas empresas optam por compartilhar sua capacidade logística com outras empresas ou contratar as atividades logísticas a fim de que sejam desempenhadas por empresas especializadas em fornecer tais serviços, chamados de terceiros. Langley et al. (2009) atribuem ao PSL o entendimento de ser uma organização externa que executa todas ou parte das atividades e funções logísticas de uma companhia.

A tendência inicial de processos de terceirização logística, que contribui para a formação do PSL surgiu da falta de especialização nos processos de distribuição, concentrados, primeiramente nas atividades de armazenagem e transporte, ou seja, as chamadas funções básicas da logística. Mais tarde, as empresas que terceirizavam com uma visão de obter vantagens e facilitar a integração da cadeia de suprimentos, perceberam que poderiam ser entendidas como parte da cadeia. Já as organizações que terceirizavam por razões operacionais e custos, restringiram o envolvimento do PSL somente às funções básicas da logística (BOLUMOLE, 2001; CHRISTOPHER; TOWILL, 2001). Para Stefansson (2005) existe na literatura uma aparente mistura de terminologia nos diferentes serviços executados pelo PSL. Apesar disso, a maioria dos PSL incluem as mesmas atividades ou apresenta pequenos ajustes no portfolio oferecido.

Segundo Power et al. (2007) e Langley et al. (2009) em uma sequiência histórica de 14 anos de pesquisas sobre PSL, consideram que os principais serviços terceirizados com estes agentes são:

- Transporte interno (nacional) e externo (internacional);

- Despacho aduaneiro;

- Armazenagem e administração de estoque;

- Transferências de produtos entre fábricas e reposição de peças e produtos;

- Serviços de cross-docking;

- Serviços de etiquetagem, packing e formação de kits;

- Logística reversa (retorno de defeitos, reparos, produtos);

- Auditoria de frete e pagamentos;

- Planejamento de armazenagem e transporte;

- Serviços e soluções de tecnologia de informação voltada para logística; 
- Gestão de transportadoras, de frota e sistemas de monitoramento de frota;

- Serviços de consultoria, projetos e coordenação logística em CS;

- Serviço de atendimento a clientes e sistemas de informações;

- Recepção e processamento de pedidos;

- Quarteirização logística (gestão de terceiros que exercem as operações logísticas);

- Transferência de recursos (como locação de empilhadeiras e mão-de-obra);

- Apoio as atividades de marketing

\subsubsection{O mercado de serviços logísticos e sua importância}

A logística é hoje um elemento fundamental no contexto da Gestão da Cadeia de Suprimentos (SCM - Supply Chain Management) e as empresas que utilizam PSL passam a ter nele, uma figura chave para o desenvolvimento de sua cadeia de suprimentos (PIRES, 2004). Autores como Svenson (2003) destacam que a tendência de muitas empresas é subcontratar um maior número de atividades no fluxo outbound (jusante) e menor no inbound (montante), mantendo maior dependência nos processos a jusante do que a montante. Dados comprovados na pesquisa de Jaafar e Rafiq (2005) apontam que cerca de $4 \%$ das contratações são a montante e $52 \%$ a jusante. Independente da relação no fluxo logístico, o PSL ganha espaço e deixa o cliente mais dependente, à medida que pesquisas apontam à redução nos ativos logísticos como um dos principais fatores que levam a terceirização desses serviços.

Apesar dos serviços mais importantes ainda serem transporte e armazenagem, muitos outros têm sido incorporados pelo PSL no intuito de atender aos clientes, principalmente de fortalecer os serviços e agregar valor às suas cadeias de suprimentos.

Para Simchi-Levi et al. (2003), o processo de terceirização logística oferece vantagens e desvantagens. Assim, a grande desvantagem seria a perda de controle de uma função específica por parte do contratante. Já as vantagens seriam:

- Foco nas forças essenciais - a utilização de PSL permite a empresa focar-se em competências centrais;

- Oferecer flexibilidade tecnológica - à medida que a tecnologia avança, o PSL tende a atualizar seus recursos, o que é parte de seu negócio. Já para as empresas clientes, isso exige investimentos nem sempre disponíveis;

- Outras flexibilidades - Dispor de opções geográficas para diversos serviços que o PSL pode oferecer.

O Quadro 2, baseado em Power et al. (2007), Selviaridis e Spring (2007) e Langley et al. (2009), resume os fatores que vêm favorecendo a utilização dos PSL. 
Quadro 2 - Fatores que favorecem a utilização dos PSL Fatores que favorecem a utilização dos PSL

\begin{tabular}{|l|l|}
\hline Proliferação de novos produtos & Soluções em IT \\
\hline Globalização & Busca de Integração na CS \\
\hline Maior exigência de Serviços na CS & Ter relacionamentos mais fechados \\
\hline Menores ciclos de vida (vestuário, eletrônica) & Reduzir parceiros nas operações logística \\
\hline Mercado mais seguimentado & Conhecimento específico sobre uma operação \\
\hline Forte pressão por melhoria nos preços & Segurança nas operações logísticas \\
\hline Ênfase das empresas na gestão da CS & Necessidade de soluções em embalagens \\
\hline Melhoria nos serviços aos clientes & Flexibilidade na execução de serviços \\
\hline Surgimento de novas tecnologias em logística & Preparação para flutuações da demanda \\
\hline Inovações tecnológicas em armazenagem e transporte & \\
\hline
\end{tabular}

Fonte: Autoria própria (2010)

Autores como Vaidyanathan (2005) reforçam que um PSL com conhecimento em cadeia de suprimentos e relações globais é uma opção estratégica para oferecer soluções inovadoras em logística, no controle de inventário, na administração da demanda, encontrando melhores níveis de alocação, transporte multimodal, armazenagem, oferta de Tecnologia de Informação e Comunicação (TIC), cobertura global e capacidade de atuar na manufatura e serviços da indústria. As empresas tendem a ganhar competitividade com serviços logísticos sob medida.

Para Sinkovics e Roath (2004), o relacionamento entre o PSL e um produtor gera flexibilidade operacional que aumenta a orientação competitiva pelo impacto logístico no desempenho mercadológico. Para eles, a flexibilidade operacional é a capacidade mais saliente. Se a empresa satisfaz as necessidades e expectativas dos clientes melhor que seus concorrentes, conseqüentemente, constroem-se uma melhor relação e aumentam-se as possibilidades de retenção do cliente. Por essa razão, produtores podem alavancar e melhorar suas capacidades por trabalhar com o PSL. Para esses autores, o fato de o produtor não precisar desenvolver eficiências logísticas ajuda-o internamente, além de melhorar sua relação com o mercado. Chapman et al. (2003) vêem a indústria logística como um exemplo clássico de nascimento e desenvolvimento de um novo e vital serviço, transformado frequentemente de um restrito serviço de transporte para um amplo serviço de atendimento às necessidades logísticas dos clientes. Essa visão demonstra a flexibilidade que o PSL tem no mercado quanto à possibilidade de oferta de serviços. Geralmente, o PSL agrega funções à medida que estende o relacionamento com seu cliente, atingindo maior entendimento e maior confiabilidade no processo operacional e nos serviços prestados a ele. Com isso ganha confiança e aumenta seu escopo de ação, construindo um portfolio mais amplo de atividades.

Numa visão mais atualizada, o PSL pode estar entrando em uma quarta onda, cuja evolução dos conceitos colaborativos na cadeia de suprimentos, bem como a visão de gestão da cadeia como instrumento de diferenciação e vantagem competitiva, incorpora ao PSL novas atribuições. Isso, 
combinado com a utilização de ferramentas tecnológicas, diferencia o PSL de um mero executor para um agente integrador da cadeia (LANGLEY et. AL., 2009; LIEB, 2005).

O PSL deve ter habilidade para gerar competências a seus clientes, criando uma parceria de soluções logísticas, bem como ter capacidade para aprender com seus clientes. Desta forma, todo novo cliente ou troca de clientes, terá uma curva de aprendizagem, gerando novas habilidades e competências ao PSL (HALLDÓRSSON; SKJOTT-LARSEN, 2004).

Hoek (2001) diz que o PSL teria relevantes oportunidades para expandir seus serviços, uma vez que já era uma das principais empresas com ações voltadas para a cadeia de suprimentos, movendo-se para áreas funcionais, por meio dos serviços tradicionais, como em atividades de produção e marketing. Esse citado autor também relata que, com a expansão dos processos de integração na cadeia de suprimentos o mercado tornar-se ainda mais dependente do PSL. Já Langley et al. (2009) destacam a importância do relacionamento do PSL com o cliente, como forma de expandir os serviços. Eles apontam como expectativa dos clientes a necessidade do PSL ser mais dinâmico na oferta de tecnologia e soluções operacionais, tais como recepção de pedidos e rastreamento de produtos.

Desde meados da década de 1990 os PSL têm ampliado os serviços na intenção de atender o desejo do cliente para serviços dedicados. Recentemente, as empresas industriais têm demandado mais serviços no final da cadeia de suprimentos, como instalação de equipamentos, serviços de reparo, montagem de kits, etc. Essa tendência do mercado tem levado os PSL a focarem um segmento específico de empresas ou de negócio. Isso tem sido visto como um fator de diferenciação dos PSL (LIEB, 2008).

\subsubsection{Sobre gestão colaborativa e o papel do PSL}

A diversidade de atividades executada pelo PSL, bem como sua capacidade para atuar na cadeia assumindo novas atribuições de responsabilidade do seu cliente é reconhecida por diversos segmentos. Quanto mais serviços o PSL incorpora em seu portfolio, mais especializado se torna, podendo assim conquistar novos clientes e mercados (LANGLEY et al., 2009).

Também, pela complexidade em se definir serviços integrados na cadeia, as empresas (PSL e cliente) necessitam ter o foco ajustado para as operações que desejam, bem como valores e fundamentos gerenciais relativamente correlacionados. Mesmo assim, o risco inerente ao se compartilhar negócios estará presente. A especialização do PSL na realização de atividades básicas (como armazenagem e transporte) tende a contribuir para os negócios de empresas que não têm este conhecimento e a medida que agregam novas atividades favorecem a integração.

O sincronismo de diversas atividades coordenado por um único agente, como no caso de um PSL, ajuda no desempenho da cadeia. Chapman et AL., (2003) relatam que os clientes buscam ter 
um PSL com maior habilidade para desenvolver os serviços logísticos, e apontam isso como um caminho para o PSL partir para ações de coordenação e inovação. Já as sugestões de Pagell (2004) contemplam pontos importantes que devem ser observados em processos de integração dos serviços operacionais em cadeia de suprimentos pelo PSL:

- Estrutura - ter estrutura suficiente para servir o fluxo de seu cliente;

- Cultura - saber lidar com a cultura interna e as diferentes culturas de seus clientes;

- Comunicação - estar preparado para comunicação em tempo real;

- Medidas e recompensas - ter habilidade para trabalhar avaliando sua operação, tanto interna quanto externa, atrelando aos resultados, recompensas e penalidades;

- Consenso/Integração - ter nas práticas operacionais visão de consenso e de integração entre os agentes;

- Tamanho da operação - Conseguir estabelecer com o cliente se há capacidade operacional para atender os serviços operacionais contratados.

Neste caminho, o apoio tecnológico para transmissão e transação de dados tem se tornado um aliado do PSL. Com TIC (Tecnologia da Informação e Comunicação) atualizada, novas configurações se desenham para a gestão logística através do PSL, como sugerem diversos autores (HOEK, 2006; LANGLEY et al., 2009; VISSER et al., 2004), ao definirem os 4PL como integradores ou líderes logísticos numa função maior de coordenação do que de operação. Já Barratt (2004) atribui a essas novas tecnologias muitas das soluções surgidas na cadeia de suprimentos. De fato, elas contribuem muito com a gestão da cadeia, por serem ferramentas importantes e fundamentais para o relacionamento e operação. Entretanto, essas soluções não ganham consistência sem coordenação e conhecimento. Considerando a capacidade do PSL para incorporar serviços e responsabilidades, esse papel poderia ser atribuído a ele.

Diversos autores (HOEK, 2006; LANGLEY; ALLEN, 2005; VISSER et al., 2004) destacam a abrangência e responsabilidade deste provedor na cadeia de suprimentos, com a tendência evolutiva de atuar em processos de coordenação e gestão indireta de terceiros. A questão sobre este novo papel para o PSL está no fato de que um processo de quarteirização (4PL) pode gerar uma suposta tendência de agregar custos desnecessários, por criar uma taxa extra sobre serviços ou estrutura que um PSL ou o terceiro já possua. Já Stefansson (2005) apresenta a ideia de um intermediário logístico como um caminho para melhorar custos e ampliar serviços, desempenhando o papel de coordenador e gestor das atividades através de uma estrutura própria e, quando necessário, de terceiros. Ter um sistema misto de recursos próprios e de terceiros para operações na cadeia de suprimentos pode ajudar na melhoria dos custos, porque possuir toda estrutura necessária a uma cadeia, além de cara, operacionalmente pode ser complexo ou até mesmo inviável. Isso pode 
oferecer ao PSL maior percepção do nível de serviço prestado ao cliente.

Considerando o fato de que os serviços contratados de um PSL geralmente são marcados por prestação de serviços em um prazo mais longo do que simplesmente uma relação transacional, pode-se dizer que isto favorece a relação colaborativa, uma vez que segundo Kanagaretnam et al., (2010) repetidas interação (que é o caso dos serviços prestados pelo PSL) aumenta a confiança e a reciprocidade entre as empresas, com ou sem transparência. Esta por sua vez, é importante na construção da confiança envolvida nos negócios tal como a divisão de responsabilidades e de investimentos, por exemplo.

Também, para Ryu et al., (2009) a confiança só pode ser construída através da experiência entre as empresas no longo prazo, que é a caso das relações dos PSL. Para ele a aproximação operacional influencia a confiança, mas não influência o compromisso existente entre as empresas. No entanto, o compromisso é construído sobre fundamentos existente na confiança entre as empresas. Segundo os autores, o desenvolvimento da confiança e do compromisso por meio da interação de duas empresas, como no relacionamento entre PSL e cliente, promove colaboração entre as demais empresas da CS e ajuda a sustentar a colaboração.

Além dessa pressuposta contribuição do PSL a gestão colaborativa Holweg e Pil (2008) relata que uma característica comum para resolver muitos problemas existentes na CS (chamado por ele dos "males" da CS) é transferir informações sem atraso entre os parceiros. Neste papel, o PSL tem se mostrado um agente capaz de responder a este serviço, facilitando e provendo visibilidade aos diferentes tipos de informações necessárias a uma cadeia e seus agentes.

Considerando os diversos fatores associados à cadeia de suprimentos, como sua complexidade, necessidade de se ter agilidade, atuar com diversos agentes e diferentes atividades, pode-se afirmar que, as oportunidades de negócios para o PSL são inúmeras. Autores como Fawcett e Magman (2002) citam a possibilidade de o PSL conquistar mais espaço nas cadeias de suprimentos na medida em que empresas integrem os processos com seus agentes, como na gestão da demanda, que exige tecnologia e coordenação. A adoção do PSL com múltiplas atividades pode reduzir o número de fornecedores, e vai ao encontro do que foi observado por Cristopher (2006) a respeito da escolha certa de parceiros na cadeia de suprimentos. Esse autor reforça o fato de que, para a gestão da cadeia, é melhor ter um número reduzido de fornecedores comprometidos do que muitos fornecedores dispersos e sem comprometimento.

Para o PSL, é importante entender a importância dos ativos, não só da estrutura física e operacional (como instalações e equipamentos), como os componentes tecnológicos que favorecem o relacionamento com o cliente. Nesse aspecto, ferramentas tecnológicas, aliadas com novos métodos de gestão, são instrumentos que devem fazer parte da estrutura e do conhecimento do PSL. Essas ferramentas, segundo Fliedner (2003), favorecem o processo de integração na cadeia, e 
podem ser utilizadas pelo PSL para melhorar os processos operacionais da cadeia de suprimentos que envolvem os diversos agentes, bem como para conquistar novas atividades e clientes.

\section{Estudo de caso}

Nesta etapa, o estudo apresenta como o PSL pesquisado desenvolve seu trabalho, apresenta as empresas pesquisadas e relata os principais fatores que influenciam na decisão ou não de se escolher o mesmo PSL da empresa concorrente.

\subsection{Operação atual do PSL}

De forma resumida, o PSL estudado é responsável pela gestão de compras e estoques para atender aos restaurantes de seus clientes. Nessa atuação estão incluídas operações de armazenagem, distribuição ponto a ponto, transportes, transferências para centros de distribuição no país, gestão financeira da cadeia, planejamento logístico, planejamento fiscal, serviço de campo para avaliar as entregas e o comportamento dos pontos de venda e coordenação das operações de abastecimento (inbound) na cadeia.

Para efetuar sua atribuição, o PSL além da estrutura de armazenagem, possui uma frota exclusiva de veículos e uma equipe própria para as operações, contando com todo um sistema integrado com fornecedores e se seus clientes (corporação e pontos de venda), gerenciando não só a operação de entrega, como a demanda e estoques junto aos supridores. Todos os pedidos dos restaurantes e pontos de venda são recebidos, processados e automaticamente alimentam o sistema interno do PSL para o abastecimento e a distribuição física aos restaurantes, além de gerar todas as informações necessárias para fornecedores, históricos de venda, estatísticas, apoio a marketing, etc.

O PSL na execução e coordenação das atividades logísticas foca seu trabalho segundo os objetivos traçados pelo seu cliente, integrando todas as etapas necessárias para contribuir com a operação de abastecimento dos restaurantes e pontos de venda. Nesse sentido, orienta-os em como: agilizar o recebimento, melhor estocar os produtos, efetuar um pedido adequado a demanda de venda, participar dos lançamentos de novos produtos, atuar junto aos fornecedores no abastecimento dos centros de distribuição, manter um sistema de pedidos e controle de dados de todos os pontos, efetuar a distribuição e administrar todas as variáveis da operação. No geral, fornece todo o suporte operacional e informações necessárias à seus clientes para gerenciarem sua cadeia de suprimentos.

Este sistema todo está apoiado por processos de qualidade que balizam o recebimento e a distribuição dos produtos pelos Centros de Distribuição (CD) segundo os padrões exigidos e auditados pelos clientes. Outro fator relevante e forte em toda a operação é a estrutura de TIC que sustenta os aplicativos voltados a logística, como ERP (Enterprise Resources Planning), WMS 
(Warehouse Management System), Portais de Relacionamento com restaurantes e fornecedores via internet, EDI (Eletcronic Data Interchange), CPFR (Collaborative Planning, Forecasting and Replenishment), e uma forte base e banco de dados para sustentar as informações necessárias ao sistema.

As diversas atividades executadas pelo PSL, descritas a seguir, estabelecem a dimensão de seu papel na execução logística e a importância de seu apoio nos processos de integração da cadeia de suprimentos de seus clientes. Desta forma, baseado neste sistema, pode-se classificar os processos logísticos exercidos por ele em:

- Atividades operacionais (funcionais) - Atividades exercidas no dia-a-dia para manter o abastecimento dos restaurantes e pontos de venda e a relação com fornecedores e corporação;

- Serviços de integração - informações à corporação, transmissão de informação aos fornecedores e métodos utilizados para integração do sistema do PSL internamente e externamente, facilitando e contribuindo com a operação;

- Métodos de avaliação dos serviços - como é avaliada o desempenho do sistema, segundo os interesses da cadeia.

O Quadro 3 especifica as diversas atividades realizadas pelos PSL. 
Quadro 3 - Atividades realizadas pelo PSL

\begin{tabular}{|c|c|c|c|}
\hline Atividades & Funcional//Operacional & Serviço de Integração & Métodos de Avaliação \\
\hline Suprimentos & $\begin{array}{l}\text { Pedido de compra, coleta do } \\
\text { produto, padronização de } \\
\text { entrega, coordenação de } \\
\text { produtos testes, etc. }\end{array}$ & \begin{tabular}{|c|} 
Programação de Pedidos, \\
previsão de demanda, dados e \\
informações histórica, \\
interligação via sistemas \\
\end{tabular} & $\begin{array}{l}\text { índice de Ruptura de } \\
\text { abastecimento }\end{array}$ \\
\hline Armazenagem & $\begin{array}{l}\text { Recebimento, avaliação da } \\
\text { qualidade, estocagem, } \\
\text { separação, carga, gestão do } \\
\text { estoque, sistemas de } \\
\text { embalagens, modulações de } \\
\text { estocagem, etc. } \\
\end{array}$ & $\begin{array}{l}\text { WMS e sistemas de qualidade } \\
\text { integrado com clientes } \\
\text { fornecedores }\end{array}$ & $\begin{array}{l}\text { Produtividade de armazém e } \\
\text { indicadores de qualidade de } \\
\text { fornecimento }\end{array}$ \\
\hline Distribuição & $\begin{array}{l}\text { Entrega programada ponto-a- } \\
\text { ponto com horário marcado }\end{array}$ & $\begin{array}{l}\text { Informação que permite ao } \\
\text { restaurante saber sobre a } \\
\text { entrega, sistema de } \\
\text { roteirizadores e gestão de } \\
\text { frotas } \\
\end{array}$ & $\begin{array}{l}\text { Entrega no horário } \\
\text { performance na descarga }\end{array}$ \\
\hline Serviço ao Cliente & $\begin{array}{l}\text { Recepção dos pedidos de } \\
\text { abastecimento, controle de } \\
\text { reclamações de produtos, e } \\
\text { serviço de campo }\end{array}$ & $\begin{array}{c}\text { Portal de comunicação com o } \\
\text { restaurante, Recomendação } \\
\text { do pedido de compra, avisos } \\
\text { de testes, recall, etc. } \\
\end{array}$ & $\begin{array}{l}\text { Pesquisa de satisfação do } \\
\text { cliente }\end{array}$ \\
\hline Dados e Informações & \begin{tabular}{|c|} 
Históricos de compra, venda \\
por fornecedor, restaurantes e \\
produtos
\end{tabular} & $\begin{array}{l}\text { Sistema de BI (Business } \\
\text { Inteligence) disponível para } \\
\text { Fornecedores e clientes } \\
\end{array}$ & $\begin{array}{l}\text { Pesquisa de satisfação do } \\
\text { cliente }\end{array}$ \\
\hline Suporte Operacional & $\begin{array}{c}\text { Serviços de apoio ao sistema, } \\
\text { como suporte fiscal e contábil, } \\
\text { testes de produtos e novos } \\
\text { lançamentos, distribuições } \\
\text { especiais como equipamentos } \\
\text { e promoções, gestão de custos } \\
\text { dos produtos, projetos de } \\
\text { melhoria da cadeia, } \\
\text { importação e exportação } \\
\text { (serviços aduaneiros), recall, } \\
\text { etc. }\end{array}$ & $\begin{array}{l}\text { Integração de sistemas } \\
\text { facilitar vara } \\
\text { informações }\end{array}$ & \\
\hline
\end{tabular}

Fonte: Própria autoria (2010)

\subsection{Empresas pesquisadas e a escolha do PSL}

Das oito redes de alimentação fora de casa pesquisadas, seis tem presença nacional e duas estão restritas ao estado de São Paulo. Duas delas têm mais de 500 pontos de venda, duas estão na faixa de 250 pontos e as demais não chegam a ter mais de 50 pontos. A maior concentração dos pontos de venda está em shopping e a maioria deles está localizada nas capitais ou nas grandes cidades do País (cidades acima de 200 mil habitantes).

\subsubsection{A escolha do mesmo PSL}


Nas entrevistas os autores registraram muitas informações, num primeiro momento com os gestores corporativos (que administram os pontos de venda) das redes e num segundo com os gestores dos pontos de venda, na intenção de comparar e complementar informação. O propósito também foi conseguir entender se a intenção de atuar com um PSL que serve aos concorrentes têm maior ou menor influência nas decisões dos pontos de venda ou da organização das redes, ou seja, onde o fato de utilizar o mesmo operador fica mais evidente. Com isso os autores puderam entender melhor os aspectos positivos ou negativos da decisão.

$\mathrm{Na}$ análise das informações coletadas foram destacados, os principais aspectos e considerações que influenciam na decisão de buscar um mesmo operador. Vale lembrar que este é um segmento específico e as razões aqui apresentadas não podem ser extrapoladas como as mesmas em diferentes setores. Outro aspecto a ser destacado também, é que os autores não criaram um ranking para saber o que é mais ou menos importante, ou pediram aos entrevistados para classificarem isso. As informações foram sendo coletadas e delas os autores extraíram os pontos comuns e de convergência que influenciam ou não na decisão de atuar com o mesmo operador.

O Quadro 4 faz um resumo dos fatores que influenciam na decisão da escolha ou não de um PSL por empresas concorrentes, destacando os aspectos vistos como prós e contra nesta escolha. Esta classificação foi definida pelos autores com base na pesquisa, através das informações ou mesmo da posição que os entrevistados transmitiam no momento da coleta dos dados.

Quadro 4 - Prós e contras na escolha do mesmo PSL por concorrentes

\begin{tabular}{|l|l|}
\hline \multicolumn{1}{|c|}{ Prós } & \multicolumn{1}{|c|}{ Contras } \\
\hline \hline Custos & Custos \\
Expertise do PSL & Centralização no mesmo PSL \\
Redução de investimentos & Utilização das mesmas rotas \\
Atuação Nacional & Vazamento de informações \\
Gestão de pedidos e informações & Dependência do PSL \\
TIC (tecnologia de informação e comunicação) & Sistema pré-moldado \\
Personalização das entregas & \\
Relação com fornecedores & \\
Qualidade operacional & \\
\hline
\end{tabular}

Fonte: Autoria própria (2010)

Os principais aspectos e considerações levantados estão apresentados a seguir:

Custos - Este foi um dos fatores mais citados por todos os entrevistados, sejam eles corporativos ou do ponto de venda. As citações são tanto no sentido de que o serviço pode até custar mais, quanto dos que acham que deve custar menos. Neste último caso, as citações ficam mais por conta dos gestores de loja, que focam mais o negócio com a visão única de seu ponto. Do outro lado, a visão dos gestores corporativos está no fato de que aspectos como qualidade, facilidade operacional para o ponto de venda, segurança no abastecimento e outros fatores mais, devem ser considerados e podem compensar um custo maior. Aqui, percebe-se claramente que 
todos fazem a ressalva de o 'a mais' não pode ser muito mais do que outros PSL praticam, ou das referências que possuem.

Expertise do PSL - É consenso de que o PSL em questão é um dos mais qualificados e preparados para atuar neste segmento e tê-lo junto significa obter diferenciais que outros não proporcionariam. Além disso, é destacado que por ele atender a maior rede brasileira do setor (que se caracteriza por ser muito forte em qualidade e custos),o PSL é entendido como capaz de oferecer o mesmo a eles.

Redução de investimentos - O fato do PSL assumir o estoque de seus clientes (assume comprando e mantendo estoque mínimo) é um facilitador para as redes. Isso mostrou não ser tão relevante para as redes maiores, mas se destacou nas redes menores, que pretendem crescer e investir na expansão e nos pontos de venda.

Atuação nacional - Possuir diversos centros de distribuição e atingir com seus próprios veículos e funcionários todas as capitais do país é considerado um diferencial em relação à concorrência, que na maioria dos casos terceiriza a operação quando necessária.

Gestão de pedidos dos pontos de venda e histórico de demanda - O sistema de gestão de pedidos do PSL estudado (segundo seus clientes e não clientes) se apresenta adiante dos demais. Esse é um atributo que quem tem acha muito importante e quem não é cliente gostaria de ter. Além disso, as informações e facilidades geradas pelo sistema são tidas como muito boa pelos gestores dos pontos de venda.

TIC (tecnologia da informação e comunicação) - O PSL se apresenta como um grande provedor de soluções tecnológicas e isto impressiona as empresas entrevistadas, que destacam este aparato e os benefícios para a gestão da cadeia de suprimentos. Esse é um serviço que todos concordam que sozinhos provavelmente não teriam chegado ao nível que possuem.

Personalização das entregas - $\mathrm{O}$ aspecto de se entregar com data e horário certo para os pontos aparece como um atributo muito forte, e que os PSL concorrentes ainda tem muita dificuldade em acertar este processo.

Relação com fornecedores e importação - O fato do PSL ter relacionamentos com os principais fornecedores de alimentos para redes comerciais (varejo) do setor e dominar os processos de importação leva a algumas facilidades para as empresas que desejam iniciar a operação com ele. Isso também ajuda no caso das que já operam com ele, principalmente na introdução de novos produtos ou mesmo no aperfeiçoamento ou modificação nos produtos de linha.

Problemas com a centralização num mesmo PSL - Foram citados por alguns pesquisados que se houvessem problemas que comprometessem as operações do PSL isso afetaria a todos, porque todas as operações são centralizadas em uma plataforma única de dados, e em alguns centros de distribuição as operações são compartilhadas entre diversos clientes. 
Utilização da mesma rota para entregas - A entrega compartilhada com diferentes clientes pareceu ser um ponto de conflito entre os entrevistados. É quase que consenso que isto reduz custos, mas também é consenso que gostariam de ser exclusivos. Isto pelo fato de que o desempenho de uma entrega compromete ou não a próxima, principalmente na questão relacionada ao horário da entrega.

Vazamento de informações - Todos demonstram acreditar na ética do PSL, mas é um ponto em que apresentam receios e preocupações com o potencial risco.

Dependência do PSL - Ao concentrar a operação total de abastecimento de seus pontos em um PSL, os entrevistados destacam o fato de tornarem dependente dele e que isso pode comprometer negociações com aumentos acima do esperado. Alguns lembraram também, que quanto mais o PSL concentrar clientes concorrentes, mais forte ficará sua presença nesse mercado, criando barreiras claras de entrada pra outros potenciais PSL competidores.

Sistema pré-moldado - Como o PSL já construiu plataformas de atuação com diferentes clientes, alguns consideram que isso cria um "molde padrão". Assim eles devem se moldar ao PSL e isso é visto por alguns como uma imposição.

Atendimento exclusivo - Não existir atendimento exclusivo dedicado ao cliente, com equipe focada, aparece como um atributo negativo quando os clientes analisam suas operações sendo compartilhadas com concorrentes.

Qualidade da operação e qualidade dos produtos - Este atributo é muito forte para o PSL que é reconhecidamente tido como o melhor diante de seus concorrentes. Todos afirmam que os fatores relacionados à qualidade contribuem muito para suas operações.

\section{Considerações finais}

Os principais fatores que contribuem para a escolha de um mesmo PSL identificados na literatura e que tem correlação com as informações obtidas no estudo de campo, bem como aqueles identificados no estudo de caso estão resumidos no quadro 5, e a seguir eles são discutidos e detalhados com dados e informações coletadas com os entrevistados.

Quadro 5 - Principais fatores que contribuem para a escolha de um mesmo PSL 


\begin{tabular}{|c|c|}
\hline Apontados na literatura & Identificados no caso \\
\hline Focar o próprio negócio & $\begin{array}{l}\text { Gestão de pedidos do ponto de venda, } \\
\text { históricos e visão da demanda }\end{array}$ \\
\hline Custo da operação & Personalização da entrega \\
\hline Redução de investimento & $\begin{array}{l}\text { Relação com fornecedores nacionais e } \\
\text { internacionais }\end{array}$ \\
\hline Abrangência geográfica para atendimento & $\begin{array}{l}\text { Riscos e dependencia pela centralização da } \\
\text { operação com o mesmo PSL }\end{array}$ \\
\hline Tecnologia da Informação e comunicação & Compartilhamento de rotas \\
\hline \multirow[t]{3}{*}{ Melhoria nos níveis de serviços } & Vazamento de informação \\
\hline & $\begin{array}{l}\text { Sistema operacional igual aos demais } \\
\text { concorrentes }\end{array}$ \\
\hline & Exclusividade no atendimento \\
\hline
\end{tabular}

Fonte: Autoria Própria (2010)

Focar esforços em seu próprio negócio (nas competências centrais) reduzindo custos e investimentos na logística e principalmente na formação de estoque, como também através da rede de distribuição do PSL buscar novos mercados, foram pontos que apareceram na pesquisa por ficar claro aos entrevistados que o foco das redes de alimentação é desenvolver seu próprio negócio, e a gestão e as operações logísticas exigidas na cadeia demandam tempo, investimentos e conhecimento nem sempre disponível. Exceto nas 3 maiores redes pesquisadas, as demais foram enfáticas ao afirmarem a importância deste quesito na escolha do PSL estudado.

Reduzir os custos logísticos e evitar investimentos em ativos não relacionados ao negócio da empresa foram fatores de destaque na pesquisa. A razão é porque a intenção, para maioria, é investir na expansão em novos mercados. Isto exigiria operadores com atendimento geográfico mais abrangente, podendo, com isso, obter redução de custos ao entenderem que o atendimento de novas praças pode ser feito compartilhado com outros clientes do PSL. As 4 redes de menor porte afirmam ser esse o grande diferencial para adotarem o mesmo PSL. Por possuírem plano de expansão e solicitações de franqueados para abertura em diferentes estados, a forma mais rápida e segura é se apoiar na estrutura e malha de distribuição do mesmo PSL.

Nos aspectos relacionados a melhoria e controle dos níveis dos serviços e das atividades logísticas, foi consenso entre os pesquisados reconhecerem a capacidade do PSL em relação a outros provedores. Como colocado por um dos pesquisados, se o PSL já atende a rede mais exigente do mercado, a ideia é obter, por meio dele, serviços contratados em um padrão semelhante. Aqueles que não são atendidos ainda pelo PSL, queixam-se do nível de serviço, principalmente os relacionados ao horário da entrega e ao acerto nos pedidos. Eles afirmaram conviver com situações em que, apesar de programado um dia e o período (manhã, tarde, noite) para entrega, cerca de $50 \%$ das vezes recebem produtos fora do prazo, principalmente os pontos de venda mais distantes como Norte, Nordeste e Centro-oeste do País. Além disso, os pesquisados não atendidos pelo PSL admitem que praticamente em todos os pedidos não recebem tudo que foi pedido. Nestes indicadores, os gestores dos pontos de venda gostariam de ter índices próximos aos 100\%, já os 
gestores corporativos amenizam esta importância, mas são claros de que precisariam um padrão melhor (acima de 90\%) possível de ser administrado pelos pontos de vendas. Esta posição se dá por entenderem que falhas ocorrem na cadeia de abastecimento e admitem uma margem de erro, e incluem estes indicadores como ponto fundamental para compor as negociações com o PSL.

Com indicadores de serviços melhores é possível ter maior flexibilidade e eficiência nas operações logísticas. Assim, as empresas entendem que ao buscarem o mesmo PSL, partem de premissas relacionadas a um nível de serviço maior do que já possuem, dando aos pontos de venda melhores condições de abastecimento.

Apesar de todos os pesquisados reconhecerem a capacidade do PSL na prestação de serviços logísticos para a área de alimentação fora de casa, 6 redes reconhecem que seria possível desenvolver um nível de atendimento semelhante com outros operadores, porém, o fator custo e tempo de desenvolvimento aparecem como possíveis barreiras. Segundo uma dessas redes, que já desenvolveu projetos neste sentido, o investimento em TIC e na malha de atendimento nacional tornam-se o principal fator de impedimento, pois seus custos (principalmente a amortização do investimento) pesam muito na composição do preço do serviço para o ponto de venda. Estes aspectos afetam o resultado individual de cada ponto, e num mercado dominado por franqueados a resistência torna-se o principal impedimento. Com a força tecnológica que o PSL possui, as redes conseguem sem esforços e investimentos adequar e tornar ágil a troca de informações na sua cadeia, bem como obter um leque de informações que exigiria altos investimentos se feitos isoladamente.

Todos os pesquisados, principalmente os gestores dos pontos de vendas que já utilizam o PSL, colocaram a praticidade e agilidade que é o sistema de pedidos disponibilizado via web. Para os gestores corporativos a importância do sistema de informações do PSL esta na formação de dados relacionados aos pontos de venda e aos fornecedores. As empresas que ainda não trabalham com o PSL veem isso como um bom atrativo, porém não seria só isso que definiria a escolha. Um deles alega que o que possuem hoje atende suas necessidades apesar de mais restrito comparativamente.

As redes que não utilizam o PSL veem como um bom atrativo o sistema de informação que oferecem, porém não seria só isso que definiria a escolha. Um deles alega que o que possuem atualmente atende suas necessidades apesar de ser mais restrito.

Nos fatores observados a partir do caso, o diferencial apontado pelos pesquisados na escolha do mesmo PSL deve-se a importância de se ter a gestão de pedidos do ponto de venda (incluindo o pedido sugerido) e histórico de pedidos e demanda como fator de extrema relevância para os gestores corporativos que pensam em utilizar o PSL como forma de expansão dos negócios e melhora na qualidade dos serviços. 
Outro ponto interessante e bastante valorizado pelos gestores do ponto de venda foi o fato do PSL programar entregas com horário marcado, e com compromisso de atendimento na faixa de 95\% de acerto. Isto ajuda o ponto de venda na programação de seus trabalhos, além de permitir que tenham uma gestão de estoque mais confiável com volumes menores, uma vez que se sabe o momento da chegada do abastecimento. Isto é mais evidenciado nas entrevistas com as empresas que já atuam com o PSL, pois afirmam que seu estoque é controlado num nível relativamente baixo por haver confiança no PSL. Por sua vez, escuta-se o oposto daqueles que não operam com o PSL.

O risco de executar a operação com um mesmo PSL em que o concorrente atua, em caso de alguma ruptura na operação, como num evento crítico que afetasse o PSL, não daria a empresa (ou no caso a uma das redes estudadas) nenhuma vantagem de aproveitar a repercussão disso nos pontos de venda, pois ela seria afetada também. Isto aparece como um fator lembrado por todos, mas não tão importante. Apenas uma das redes manifestou ser este fator um impedimento na contratação do PSL, tanto que para eles o ideal seria ter operações totalmente separadas, mas entendem que isso poderia não gerar ganhos em escala que favorecessem o custo final do serviço. Neste fator, também, inclui-se a relação de risco com a utilização de fornecedores nacionais e internacionais que atuam com o PSL e servem as mesmas redes.

O compartilhamento de rotas aparece como um atrativo para as redes menores sem muito poder de influência no mercado e sem condições para assumirem custos de entregas em regiões mais distantes.

Muito enfatizado, pelo maior e principal cliente, o fato do PSL estar compartilhando com os demais o mesmo sistema desenvolvido para eles, o que significaria o repasse de um diferencial competitivo adquirido aos concorrentes.

Há de se destacar que os fatores acima identificados na literatura foram apresentados com base na utilização e contratação de PSL de uma maneira genérica, sem identificar ou focar se a utilização se relaciona com contratantes concorrentes. Na intenção de complementar estes aspectos, contribuindo com a literatura, este estudo apresentou diferentes fatores que se relacionam com empresas concorrentes. Apesar disso, entende-se que à limitação do estudo esta no fato de ter analisado apenas um seguimento, com um grupo (apesar de representativo no seguimento) restrito. Como sugestão de estudos futuros, seria oportuno expandir uma análise mais generalista ao mercado podendo melhor entender os movimentos em torno da utilização de um mesmo PSL por empresas concorrentes.

No geral pode-se considerar que, para o conjunto de empresas estudadas, que a decisão de escolha ou não do PSL que atende a concorrentes não é percebido como um problema que afetará os negócios da empresa contratante. As empresas pesquisadas destacam mais fatores que favorecem a escolha de atuar com o mesmo PSL do que aqueles que impeçam a decisão. Todos os fatores 
apresentados são percebidos pelas empresas estudadas como motivadores para a escolha do mesmo PSL e os benefícios percebidos na incorporação desses diferenciais tem maior impacto na decisão do que o fato dele atender a um concorrente.

\begin{abstract}
Thinking that the logistics management attributed to an LSP (Logistics Service Providers) appears as an alternative to be adopted by companies, this article examines the outsourcing of the same LSP by competing companies. Through a study of multiple cases eight companies in the food market and a PSL were researched in the intention of obtaining the main decision factors to choose or not the same provider. The study presents the main factors investigated and concluded, for the cases studied, that the fact of the PSL to serve competitors is not an impediment to their employment.
\end{abstract}

Key-words: logistics service provider; competitors; logistics.

\title{
Referências
}

ASHENBAUM, BRYAN; MALTZ, ARNOLD; RABINOVICH, ELLIOT. Studies of trends in third-party logistics usage: what can we conclude? Transportation Journal, summer, 44, 3, p. 39, 2005.

AYERS, J. B. Handbook of supply chain management. Flórida, CRC Press-LLC, 2001.

BALLOU, R. H. Gerenciamento da cadeia de suprimentos. Porto Alegre, Bookman, 2001.

BARRATT, M. Understanding the Meaning of collaboration in the supply chain. Supply Chain Management: An International Journal. Vol. 9 n.1, pg. 30-42, 2004.

cross ref

BERGLUND, M. et al.. Third-Party Logistics: Is there a Future? International Journal of Logistics Management, 10, 1, pg. 59, 1999.

cross ref

BOLUMOLE, Y. A. The supply chain role of third-party logistics providers. International Journal of Logistic Management, v. 12, n.2, pg. 87, 2001.

cross ${ }^{\text {ref }}$

CHAPMAN, R. L. et al.. Innovation in logistics services and the new bussiness model: a conceptual framework.

International Journal of Physical Distribution \& Logistics Management. Vol. 33 n. 7, pg. 630-650, 2003. crossef

CHRISTOPHER, M.; TOWILL, D. An integrated model for the design of agile supply chains. International Journal of Physical Distribution \& Logistics Management, vol. 31 n. 4, pg. 235-246, 2001.

crossef

Christopher, M. Creating resilient supply chains. Disponível em: 〈http://www.granfield.ac.uk>. Acesso em: 28 mar. 2006.

DORNIER, PHLIPPE-PIERRE et al.. Logística e operações globais. Atlas, São Paulo, 2000.

EISENHARDT, K. M. Building theories from case study research. Academy of Management Review, vol. 14, n. 4, pp. 532-550,1989. 
FAWCETT, S. E.; MAGNAN, G. M. The rhetoric and reality of supply chain integration. International Journal of physical distribution \& Logistics Management, vol. 32, n.5, pg. 339-361, 2002.

cross ${ }^{\text {ref }}$

FIGUEIREDO, RENATA. Seleção de prestadores de serviços logísticos - Adequando o processo seletivo a cada necessidade. Artigos Cel-Coppead - UFRJ - 2005, disponível em: <http://www.cel-coppead.com.br>. Acesso em: 09 nov. 2005.

FLIEDNER, G. CPFR: an emerging supply chain tool. Industrial Management \& Data Systems. 103(1), 14-21, 2003.

HALLDÓRSSON, A.; SKJOTT-LARSEN, T. Developing logistics competencies through third party logistics relationships. International Journal of Operations \& Production Management; Vol. 24; n.2, pp.192-206, 2004. crossef

HOEK, R. I. V. The contribution of performance measurement to the expansion of third party logistics alliances in the supply chain. International Journal of Operations \& Production Management, Vol.21, n. 1/2 , pp. 15-29, 2001. cross ref em: 30 mar. 2006.

UPS logistics and to move towards 4 PL - or not? Disponível em: <http://www.csmp.org >. Acesso

HOLWEG, M.; PIL, F. Theoretical perspectives on the coordination of supply chains. Journal of Operations management. Vol. 26, n.3, pp. 389-406, 2008.

cross ref

JAAFAR, H.S.; RAFIQ, M. Logistics outsourcing practices in the uk: a survey. International Journal of Logistics: Research and Applications, vol. 8, n. 4, pg. 299-312, 2005.

cross ref

KANAGARETNAM, K. et al.. Trust and reciprocity with transparency and repeated interactions. Journal of Business research, v.63, n.1, pg. 241-247, 2010.

cross ref

KNEMEYER, A. M.; MURPHY, P. R. Is the glass half full or half empty? An examination of user and provider perspectives towards third-party logistics relationships. International Journal Of Physical Distribution \& Logistics Management, V. 35, n. 10, pg. 708-727, 2005.

crossef

LANGLEY et al.. 2009 third-party logistics. Results and findings of the $14^{\text {th }}$ annual study. Disponível em <http://www.3plstudy.com>. Acesso em: 19 set. 2010.

LANGLEY, C.; JOHN JR.; ALLEN, G. R. Third-party logistics study 2004. Results and Findings of the 2004, Ninth Annual Study. Disponível em: <http:// www.tligatech.edu>. Acesso em: 16 ago. 2005.

LAPIERRE, L. Gerir é criar. RAE- Revista de Administração de Empresas. vol. 45 n. 4 pp.108-113, 2005.

LIEB, R. C. The 3 PL industry: where it's been, where it's going. Supply Chain Management Review, set, v. 6, pg. 20-27, 2005.

The year 2007 survey - Provider CEO perspectives on the current status and future prospects of the third party logistics industry in the Asia-Pacific region. International Journal of Physical Distribution \& Logistics Management, vol. 38, n.6, pp. 495-512, 2008.

cross ref

LONSDALE, C.; COX, A. The historical development of outsourcing: the latest fad? Industrial Management \& Data Systems, vol. 100, n.9, pp. 444-450, 2000.

cross ref 
MCIVOR, R. Outsourcing: insights from the Telecommunications Industry. Supply Chain Management: An International Journal, V. 8, n. 4, pg. 380-394, 2003.

cross ref

PAGELL, MARK. Understanding the factors that enable and inhibit the integration of operations, purchasing and logistics. Journal of Operation Management, v. 22, pg.459-487, 2004.

cross ref

PIRES, S. R. I. Gestão da cadeia de suprimentos - conceitos, estratégias, práticas e casos. Editora Atlas, edição 1, São Paulo, 2004.

POWER, D; SHARAFALI, M; VIKRAM, B. Adding value through outsourcing contribution of 3PL services to customer performance. Management Research News, vol. 30, n. 3, pp. 228-235, 2007.

cross ref

RYU, I.; SO, S.; KOO, C. The role of partnership in supply chain performance. Industrial Management \& Data Systems. v. 109, n. 4, p. 496-514, 2009.

cross ref

SELVIARIDIS, K.; SPRING M. Third party logistics: a literature review and research agenda. The International Journal of Logistics management, vol. 18, n. 1, pp. 125-150, 2007.

cross ${ }^{\text {ref }}$

SIMCHI-LEVI, D.; KAMINSKY, PH.; SIMCHI-LEVI, E. Cadeia de suprimentos. Porto Alegre, Bookman, 2003.

SINKOVICS, R. R.; ROATH, A. S. Strategic orientation, capabilities, and performance in manufactures - 3PL Relationships. Journal of Business Logistics, Vol. 25, n. 2, pg. 43, 2004.

cross ref

SKJOETT-LARSEN, T.; THERNOE, C.; ANDERSEN, C. Supply chain collaboration: theoretical perspectives and empirical evidence. International Journal of Physical Distribution \& Logistics Management, 33(6), 531-549, 2003.

cross ref

STEFANSSON, G. Collaborative logistics management and the role of third-party service providers. International Journal Of Physical Distribution \& Logistics Management. V. 36, n.2, pgs. 76-92, 2005.

SVENSSON, G. Sub-contractor and customer sourcing and the occurrence of disturbances in firms inbound and outbound logistics flows. Supply Chain Management: an International Journal, v. 8, n. 1, pg. 41-56, 2003.

cross ${ }^{\text {ref }}$

VAIDYANATHAN, G. A framework for evaluating third party logistics. Communications of the ACM. Vol. 48, n.1 pgs. 89-94, 2005.

VIJAYVARGIYA, A.; DEY, A. K. Na analytical approach for selection of a logistics provider. Management Decision, vol. 48, n. 3, pp. 403-418, 2010.

cross ${ }^{\text {ref }}$

VISSER, E.; KONRAD, K.; SALDEN, R. Developing $4^{\text {Th }}$ Party Services: Empirical Evidence on the Relevance of Dynamic Transaction-cost Theory for Analyzing a Logistic System Innovation. $44^{\text {Th }}$ European Regional Science Association - ERSA 2004 Congress, 2004.

VIVALDINI, M.; PIRES, S. R. I. Operadores logísticos - integrando operações em cadeias de suprimento. Editora Atlas, São Paulo, 2010.

\section{Dados dos autores:}

Nome completo: Mauro Vivaldini 
Filiação institucional: Universidade Metodista de Piracicaba - UNIMEP

Departamento: Programa de Pós-Graduação em Administração (Mestrado e Doutorado)

Função ou cargo ocupado: Professor Titular

Endereço completo para correspondência (bairro, cidade, estado, país e CEP): Rua Pedro Cereser, 165 - Res. Paineiras - Itupeva - SP - Brasil - CEP 13295.000

Telefones para contato: (11) 9616.7595 // (11) 4496-4614 // (11) 3687.2830

e-mail:mavivald@unimep.br// mvivaldini@vianetbr.com.br

Nome completo: Silvio Roberto Ignácio Pires

Filiação institucional: Universidade Metodista de Piracicaba - UNIMEP

Departamento: Programa de Pós-Graduação em Administração (Mestrado e Doutorado)

Função ou cargo ocupado: Professor Titular

Endereço completo para correspondência (bairro, cidade, estado, país e CEP): Rodovia do Açúcar, km 156 - Piracicaba - SP - Brasil - CEP 13.400-911

Telefones para contato: (19) 3124-1515 // (16) 9783-2714

e-mail: sripires@unimep.br

Enviado em: 29/12/2010

Aprovado em 12/12/2011 